\title{
PENGGUNAAN DIAPERS MEMPERLAMBAT \\ KESIAPAN TOILET TRAINNING PADA TODDLER
}

\author{
Mutmilah Tukhusnah, Nurul Kamariyah \\ (UNUSA, FIK, SI Keperawatan, jl. SMEA No 57)
}

\author{
kamariyahnurul@ymail.com
}

\begin{abstract}
ABSTRAK
Balita usia 3 tahun seharusnya sudah dilakukan pelatihan untuk menggunakan toilet, namun kenyataannya masih banyak ibu yang belum mengajarkan toilet training sehingga balita masih belum bisa untuk melaksanakan toilet training. Tujuan dari penelitian ini untuk menganalisis hubungan antara penggunaan diapers dengan kesiapan toilet training pada toddler di RW 04 Desa Keboan Anom Kecamatan Gedangan Kabupaten Sidoarjo.

Desain penelitian ini menggunakan analitik dengan pendekatan cross sectional. Populasi dalam penelitian ini adalah semua ibu yang mempunyai anak usia 18-36 bulan di RW 04 Desa Keboan Anom Kecamatan Gedangan Kabupaten Sidoarjo sebesar 56 responden. Tekhnik sampling yang digunakan yaitu probability sampling dengan metode simple random sampling. Dan Besar sampel dalam penelitian ini sebesar 49 responden. Variabel independen dalam penelitian adalah penggunaan diapers dan variabel dependen adalah kesiapan toilet training pada toddler. Pengumpulan data menggunakan kuesioner. Hasil dianalisis menggunakan uji statistik Rank Spearman dengan nilai kemaknaan $(\alpha)=0,05$.

Hasil penelitian menunjukan bahwa dari 49 responden hampir setengahnya $(46,9 \%)$ responden menggunakan diapers selama 12-24 jam/hari pada anaknya dan sebagian besar $(53,1 \%)$ memiliki kesiapan toilet training yang kurang. Hasil uji statistik Rank Spearman diperoleh hasil $\rho(0,000)<\alpha(0,05)$ sehingga terdapat hubungan antara penggunaan diapers dengan kesiapan toilet training pada toddler.

Simpulan dalam penelitian ini adalah semakin tinggi frekuensi dari penggunaan diapers maka anak akan memiliki kesiapan toilet training yang kurang. Bagi tenaga kesehatan diharapkan agar lebih sering untuk memberikan penyuluhan tentang toilet training dan bagi orang tua, khususnya ibu diharapkan juga untuk meningkatkan bimbingan dan pengarahan yang benar tentang toilet training pada anaknya.
\end{abstract}

\section{ABSTRACT}

Toddlers should have been done the training to use the toilet, but in fact there were many mothers who did not teach about toilet training to her children because of that her children were still not able to implementation toilet training. Therefore, the research was purposed to analyze the relationship between the diapers using and the readiness of toilet training in toddler in RW 04 Keboan Anom village Gedangan district Sidoarjo regency.

The design applied in this research was analytic cross sectional. The population involved 56 mothers having babies 18-36 months old in RW 04 Keboan Anom village Gedangan district Sidoarjo regency in which 49 respondents were taken as the samples by using the simple random sampling technique. The independent variable of this research is diapers using and dependent variable is the readiness of toilet training in toddler Moreover, the instruments used to collect the data were questionnaires. The collected data were then analyzed by applying Spearman's Rank test with the level of significance $\alpha=0,05$. 
The results of research showed that nearly half of the 49 respondents (46.9\%) use the diapers for 12-24 hours / day to her children and the majority (53.1\%) had poor toilet training readiness. Based on result of the statistical test, it showed that $\rho=0,000$ which meant that $\rho$ $<\alpha=0,05$ so that HO was rejected. Thus, it also proved that there was a relationship between the use of diapers and the readiness of toilet training in toddler.

In conclusions, the higher frequency use of diapers can result in the bad effect for the child, they will have a lack toilet training readiness. The medics are expected to be more frequent for providing information about toilet training and for parents, they need to increase the guidance and the direction about toilet training to their children.

Keywords: Use, Preparedness

\section{PENDAHULUAN}

Di Indonesia diperkirakan jumlah balita mencapai $30 \%$ dari 250 juta jiwa penduduk Indonesia, dan menurut Survey Kesehatan Rumah Tangga (SKRT) nasional tahun 2010 diperkirakan jumlah balita yang susah mengontrol BAB dan BAK (ngompol) di usia sampai prasekolah mencapai 75 juta anak. (Winda, 2010)

Berdasarkan penelitian Wenty (2010) di tempat pendidikan anak usia dini (PAUD) Harapan Bunda wilayah Bogangin RW V kelurahan Kedurus Surabaya, sekitar 25\% ibu masih sulit mengajarkan anak untuk latihan buang air kecil dan buang air besar pada anak usia 24 tahun dan sekitar $12 \%$ anak usia 2-3 tahun masih menggunakan popok sekali pakai saat keluar rumah ataupun di dalam rumah.

Hasil survei pendahuluan yang dilakukan oleh peneliti pada tanggal 24 Mei 2012 di RW 04 Desa Keboan Anom Kecamatan Gedangan Kabupaten Sidoarjo melalui wawancara terhadap $10 \mathrm{ibu}$ yang memiliki batita usia 18-36 bulan diperoleh data sekitar $70 \%$ ibu menyatakan bahwa anaknya masih sulit untuk dilatih buang air kecil dan buang air besar pada tempatnya dan masih terbiasa dengan penggunaan diapers. Sedangkan $30 \%$ ibu menyatakan bahwa anaknya sudah mampu dilatih buang air kecil dan buang air besar pada tempatnya meskipun anaknya memiliki kebiasaan memakai diapers.

Kebiasaan yang salah dalam mengontrol $\mathrm{BAB}$ dan $\mathrm{BAK}$ akan menimbulkan hal-hal yang buruk pada anak di masa mendatang. Dapat menyebabkan anak tidak disiplin, manja, dan yang terpenting adalah dimana nanti pada saatnya anak akan mengalami masalah psikologi, anak akan merasa berbeda dan tidak dapat secara mandiri mengontrol buang air besar dan buang air kecil. Anak-anak yang telah terbiasa dari bayi hingga agak besar menggunakan diapers, akan mengalami beberapa perbedaan dari anak-anak lainnya yang tidak menggunakan diapers. Tentu saja jika diapers itu dipakai setiap saat, bukan pada saat-saat tidak berdekatan dengan toilet saja atau dalam berpergian. Karena penggunaan diapers akan mempersulit latihan buang air sehingga anak yang menggunakan diapers memulai latihan menggunakan toilet setahun lebih lama daripada anak yang menggunakan popok kain. ( Lusia, 2011)

Penerapan toilet training pada anak, peran orang tua diharapkan untuk lebih sabar dan ulet dan menghindari stress atau tekanan yang terlalu pada anak karena hal ini dapat menyebabkan masalah jangka panjang dimana anak akan mengalami sembelit, mengompol dan merasa bersalah. Dengan memaksa anak yang tidak siap mengakibatkan ada kekuatan yang tidak perlu dan menyebabkan kemunduran yang besar dalam proses tersebut. Dalam hal ini tenaga kesehatan juga memegang peranan penting. Ada beberapa usaha yang dapat dilakukan oleh tenaga kesehatan diantaranya dalam menunjang kesiapan toilet training pada anak dengan pemberian pengetahuan tambahan terkait toilet 
training dengan penyuluhan pada ibu meliputi kesiapan balita, usia balita, dan metode yang tepat untuk pelaksanaan toilet training serta melakukan pelatihan untuk pelaksanaan toilet training. Dengan pemberian informasi tersebut maka ibu akan mengetahui tentang cara pelaksanaan toilet training, dan ibu dapat mengetahui keuntungan dari pelaksanaan toilet training tersebut.

\section{METODE}

Jenis penelitian analitik, dengan pendekatan cross sectional. Populasi

1. Data Umum

a. Karakteristik responden berdasarkan pendidikan

Tabel 5.1 Distribusi frekuensi responden berdasarkan pendidikan ibu yang mempunyai anak usia 18-36 bulan di RW 04 Desa Keboan Anom Kecamatan Gedangan Kabupaten Sidoarjo bulan Juni 2012

\begin{tabular}{cccc}
\hline No. & \multicolumn{1}{c}{ Pendidikan } & Frekuensi & Presentase (\%) \\
\hline 1. & Dasar (SD-SMP) Sederajat & 9 & 18,4 \\
2. & Menengah (SMA) Sederajat & 28 & 57,1 \\
3. & Tinggi (Akademik/PT) & 12 & 24,5 \\
\hline & Jumlah & 49 & 100,0
\end{tabular}

Sumber : Data Primer Juni 2012

Berdasarkan tabel 5.1 diketahui bahwa dari 49 responden sebagian besar $(57,1 \%)$ memiliki pendidikan menengah.

b. Karakteristik responden berdasarkan pekerjaan

Tabel 5.2 Distribusi frekuensi responden berdasarkan pekerjaan ibu yang mempunyai anak usia 18-36 bulan di RW 04 Desa Keboan Anom Kecamatan Gedangan Kabupaten Sidoarjo bulan Juni 2012

\begin{tabular}{clcc}
\hline No. & \multicolumn{1}{c}{ Pekerjaan } & Frekuensi & Presentase $(\%)$ \\
\hline 1. & Ibu Rumah Tangga & 14 & 28,6 \\
2. & Swasta & 22 & 44,9 \\
3. & Wiraswasta & 9 & 18,4 \\
4. & PNS & 4 & 8,1 \\
\hline \multicolumn{2}{c}{ Jumlah } & 49 & 100,0 \\
\hline
\end{tabular}

Sumber : Data Primer Juni 2012

$\begin{array}{cccr}\text { Berdasarkan } & \text { tabel } 5.2 & \text { diketahui } \\ \text { bahwa dari } & 49 & \text { responden } & \text { hampir }\end{array}$

c. Karakteristik berdasarkan usia adalah semua ibu yang mempunyai anak usia 18 - 36 bulan di RW 04 Desa Keboan Anom Kecamatan Gedangan Kabupaten Sidoarjo sebanyak 56 anak. Sampelnya adalah sebagian ibu yang mempunyai anak usia 18 - 36 bulan yang dalam keadaan sehat. Besar Sampel sebesar 49 responden. Cara Pengambilan Sampel dengan simple random sampling.

\section{HASIL PENELITIAN}

Hasil penelitian dari 49 responden yang terkumpul kemudian diolah dan dikelompokkan sebagai berikut : 
Tabel 5.3 Distribusi frekuensi responden berdasarkan usia ibu yang mempunyai anak usia 18-36 bulan di RW 04 Desa Keboan Anom Kecamatan Gedangan Kabupaten Sidoarjo bulan Juni 2012

\begin{tabular}{cccc}
\hline No. & Usia (Tahun) & Frekuensi & Presentase $(\%)$ \\
\hline 1. & Dewasa Muda $(20-40)$ & 41 & 83,7 \\
2. & Dewasa Tua $(41-60)$ & 8 & 16,3 \\
\hline & Jumlah & 49 & 100,0
\end{tabular}

Sumber : Data Primer Juni 2012

Berdasarkan tabel 5.3 dapat diketahui bahwa dari 49 responden hampir seluruhnya $(83,7 \%)$ adalah dewasa muda.

\section{d. Karakteristik Usia Anak}

Tabel 5.4 Distribusi frekuensi responden berdasarkan usia anak 18-36 bulan di RW 04 Desa Keboan Anom Kecamatan Gedangan Kabupaten Sidoarjo bulan Juni 2012

\begin{tabular}{crccc}
\hline No. & Usia Anak (Bulan) & Frekuensi & Presentase $(\%)$ \\
\hline 1. & $18-24$ & & 17 & 34,7 \\
2. & $25-36$ & & 32 & 65,3 \\
\hline \multicolumn{2}{r}{ Jumlah } & 49 & 100,0 \\
\hline
\end{tabular}

Sumber : Data Primer Juni 2012

Berdasarkan tabel 5.4 dapat diketahui bahwa dari 49 responden sebagian besar

e. Karakteristik Jenis Kelamin Anak
$(65,3 \%)$ memiliki anak yang berusia $25-36$ bulan.

Tabel 5.5 Distribusi frekuensi responden berdasarkan jenis kelamin anak 18-36 bulan di RW 04 Desa Keboan Anom Kecamatan Gedangan Kabupaten Sidoarjo bulan Juni 2012

\begin{tabular}{clcc}
\hline No. & \multicolumn{1}{c}{ Jenis Kelamin Anak } & Frekuensi & Presentase $(\%)$ \\
\hline 1. & Laki-laki & 16 & 32,7 \\
2. & Perempuan & 33 & 67,3 \\
\hline \multicolumn{2}{c}{ Jumlah } & 49 & 100,0 \\
\hline
\end{tabular}

Sumber : Data Primer Juni 2012

Berdasarkan tabel 5.5 dapat diketahui $(67,3 \%)$ mempunyai anak jenis kelamin bahwa dari 49 responden sebagian besar perempuan.

2. Data Khusus

a. Karakteristik penggunaan diapers pada anak

Tabel 5.6 Distribusi frekuensi responden berdasarkan penggunaan diapers pada anak 18-36 bulan di RW 04 Desa Keboan Anom Kecamatan Gedangan Kabupaten Sidoarjo bulan Juni 2012 


\begin{tabular}{clcc}
\hline No. & \multicolumn{1}{c}{ Penggunaan Diapers } & Frekuensi & Presentase (\%) \\
\hline 1. & Tidak Menggunakan Diapers & 11 & 22,4 \\
2. & Menggunakan Diapers < 12 jam/hari & 15 & 30,7 \\
3. & $\begin{array}{l}\text { Menggunakan Diapers selama 12-24 } \\
\text { jam/hari }\end{array}$ & 23 & 46,9 \\
\hline & & 49 & 100,0
\end{tabular}

Sumber : Data Primer Juni 2012

Berdasarkan tabel 5.6 dapat diketahui bahwa 49 responden dalam penelitian ini hampir setengah $(46,9 \%)$ mempunyai

kebiasaan menggunakan diapers selama 12-24 jam/hari sebanyak 23 anak.

b. Karakteristik kesiapan toilet training pada anak

Tabel 5.7 Distribusi frekuensi responden berdasarkan kesiapan toilet training pada anak 1836 bulan di RW 04 Desa Keboan Anom Kecamatan Gedangan Kabupaten Sidoarjo bulan Juni 2012

\begin{tabular}{|c|c|c|c|}
\hline No. & Kesiapan Toilet Training & Frekuensi & Presentase $(\%)$ \\
\hline 1. & Baik & 14 & 28,6 \\
\hline 2. & Cukup & 9 & 18,3 \\
\hline 3. & Kurang & 26 & 53,1 \\
\hline & Jumlah & 49 & 100,0 \\
\hline
\end{tabular}

Sumber : Data Primer Juni 2012

Berdasarkan tabel 5.7 di atas dapat diketahui bahwa 49 responden dalam dalam hal kesiapan toilet training yang penelitian ini sebagian besar $(53,1 \%)$ masih kurang sebanyak 26 anak.

c. Hubungan Penggunaan Diapers dengan Kesiapan Toilet Training

Tabel 5.8 Tabulasi silang penggunaan diapers dengan kesiapan toilet training pada anak 1836 bulan di RW 04 Desa Keboan Anom Kecamatan Gedangan Kabupaten Sidoarjo bulan Juni 2012

\begin{tabular}{|c|c|c|c|c|c|}
\hline \multirow[t]{3}{*}{ No } & \multirow[t]{3}{*}{ Penggunaan Diapers } & \multicolumn{3}{|c|}{ Kesiapan Toilet Training } & \multirow[t]{2}{*}{ Jumlah } \\
\hline & & Baik & Cukup & Kurang & \\
\hline & & $\begin{array}{c}\mathrm{n} \\
(\%)\end{array}$ & $\begin{array}{c}\mathrm{n} \\
(\%)\end{array}$ & $\begin{array}{c}\mathrm{n} \\
(\%)\end{array}$ & $\begin{array}{c}\mathrm{n} \\
(\%)\end{array}$ \\
\hline 1. & $\begin{array}{l}\text { Tidak Menggunakan } \\
\text { Diapers }\end{array}$ & $\begin{array}{c}7 \\
(63,6)\end{array}$ & $\begin{array}{c}1 \\
(9,1)\end{array}$ & $\begin{array}{c}3 \\
(27,3)\end{array}$ & $\begin{array}{c}11 \\
(100,0)\end{array}$ \\
\hline 2. & $\begin{array}{l}\text { Menggunakan } \\
\text { Diapers }<12 \text { jam/hari }\end{array}$ & $\begin{array}{c}7 \\
(46,7)\end{array}$ & $\begin{array}{c}6 \\
(40,0)\end{array}$ & $\begin{array}{c}2 \\
(13,3)\end{array}$ & $\begin{array}{c}15 \\
(100,0)\end{array}$ \\
\hline 3. & $\begin{array}{l}\text { Menggunakan } \\
\text { Diapers selama 12-24 } \\
\text { jam/hari }\end{array}$ & $\begin{array}{c}0 \\
(0)\end{array}$ & $\begin{array}{c}2 \\
(8,7)\end{array}$ & $\begin{array}{c}21 \\
(91,3)\end{array}$ & $\begin{array}{c}23 \\
(100,0)\end{array}$ \\
\hline & Jumlah & $\begin{array}{c}14 \\
(28,6)\end{array}$ & $\begin{array}{c}9 \\
(18,3)\end{array}$ & $\begin{array}{c}26 \\
(53,1)\end{array}$ & $\begin{array}{c}49 \\
(100,0)\end{array}$ \\
\hline
\end{tabular}

Sumber : Data Primer Juni 2012 
Berdasarkan tabel 5.8 menunjukkan bahwa dari 11 anak yang tidak menggunakan diapers didapatkan sebagian besar $(63,6 \%)$ memiliki kesiapan toilet training yang baik, sedangkan yang menggunakan diapers $<12$ jam/hari hanya hampir setengahnya $(46,7 \%)$ memiliki kesiapan toilet training yang baik. Dan yang menggunakan diapers selama 12-24 jam/hari hampir seluruhnya $(91,3 \%)$

\section{PEMBAHASAN}

Penggunaan Diapers

Banyak ibu yang memilih untuk menggunakan diapers pada anaknya yang mugkin dipengaruhi oleh perkembangan jaman yang semakin maju terutama pada bidang tekhnologi. Oleh karena itu, semakin banyak produk-produk diapers bermunculan dan banyak iklan yang menawarkan kelebihan dari diapers dengan harga yang relatif murah. Sesuai dengan pernyataan Diena (2009) bahwa diapers bukan lagi suatu hal yang sulit didapat karena sudah banyak dijual misalnya toko, pasar swalayan, atau supermarket yang menjual diapers jadi diapers bisa didapat dimana saja dan kapan saja terutama di kota-kota besar sehingga ini menjadi alasan ibu menggunakan diapers untuk anaknya, khususnya ibu yang tidak mau repot dengan hal perawatan anak.

Penggunaan diapers dapat dipengaruhi oleh beberapa faktor antara lain pendidikan, pekerjaan, dan usia ibu. Pendidikan ibu akan mempengaruhi penggunaan diapers pada anaknya karena dengan adanya pendidikan yang semakin tinggi, ibu akan memiliki wawasan yang luas dan lebih mudah untuk menerima perubahan jaman daipada ibu yang yang berpendidikan rendah sehingga ibu yang memiliki pendidikan tinggi lebih memilih gaya hidup modern dan akan lebih condong untuk meninggalkan kebiasaan lama seperti penggunaan popok kain dan memiliki kesiapan toilet training yang kurang.

Hasil uji Rank Spearman dengan cara menggunakan SPSS menunjukkan $\mathrm{p}=$ $0.000, \alpha=0,05$ maka $\mathrm{p}<\alpha$ maka H0 ditolak artinya ada hubungan penggunaan diapers dengan kesiapan toilet training pada toddler (18-36 bulan) di RW 04 Desa Keboan Anom Kecamatan Gedangan Kabupaten Sidoarjo.

lebih memilih untuk menggunakan diapers pada anaknya.

Pekerjaan juga dapat mempengaruhi ibu untuk menggunakan diapers pada anaknya. Ibu yang memiliki pekerjaan swasta lebih mempunyai sedikit waktu dalam mengasuh anaknya dibandingkan dengan ibu rumah tangga atau ibu yang bekerja PNS dan wiraswasta sehingga lebih memilih praktis untuk menggunakan diapers pada anaknya dengan alasan agar pengasuh anaknya tidak terlalu repot karena sebagian besar ibu yang bekerja swasta memilih memberikan tanggung jawab untuk merawat anaknya pada neneknya. Pekerjaan juga mempengaruhi status sosial ekonomi keluarga sehingga mempengaruhi penggunaan diapers pada anak. Rata-rata masyarakat atau keluarga dengan tingkat sosial ekonomi yang cukup baik akan lebih memilih menggunakan diapers pada anaknya karena kelebihan dari diapers seperti kenyamanan dan kepraktisannya.

Usia ibu juga dapat mempengaruhi dalam hal penggunaan diapers pada anak. Pada usia ini memang sering dihubungkan dengan masa subur atau usia produktif dalam menapak karir yang penuh kesibukan di luar rumah sehingga ibu lebih dominan untuk memilih dalam penggunaan diapers pada anaknya. Ibu yang memiliki usia lebih muda mempunyai kebiasaan yang dominan terhadap ketergantungan penggunaan diapers pada anaknya bila dibandingkan dengan usia ibu yang lebih tua.

Kesiapan Toilet Training 
Ada 3 unsur yang mempengaruhi dari kesiapan toilet training yaitu fisik, psikologi dan kognitif. Pada penelitian ini kesiapan pada unsur fisik hampir seluruhnya sudah memenuhi begitu juga pada kesiapan unsur psikologi anak yang sebagian besar sudah memenuhi untuk penerapan toilet training. Tetapi pada unsur kesiapan kognitif anak yang menjadi responden hanya hampir setengah saja yang memenuhi untuk kesiapan toilet training. Dengan kesiapan kognitif yang kurang tersebut menyebabkan banyak anak yang masih mengalami keterlambatan toilet training. Kesiapan toilet training pada anak diantaranya dapat dipengaruhi oleh adanya faktor pendidikan, pekerjaan, usia ibu, usia anak dan jenis kelamin anak.

Pendidikan ibu akan mempengaruhi kesiapan toilet training pada anaknya akan mengalami kesulitan karena ibu masih awam terhadap konsep toilet training. Hal ini sesuai dengan pernyataan Warner\&Kelly (2006) bahwa semakin tinggi pendidikan ibu akan mempengaruhi kesiapan toilet training, karena dengan pendidikan yang tinggi ibu semakin mudah paham mengenai konsep toilet training pada anak.

Pekerjaan ibu juga dapat mempengaruhi kesiapan toilet training pada anak. Ibu dengan pekerjaan swasta memiliki waktu yang yang sempit dan seringkali disibukkan oleh pekerjaan sehingga membuat ibu jarang memberikan stimulasi pada anaknya, khususnya pemberian stimulasi dalam penerapan toilet training. Sehingga anak yang minim mendapatkan stimulasi dari orang tua dapat mengakibatkan anak tersebut memiliki kesiapan toilet training yang kurang bila dibandingkan dengan anak yang sering diberikan stimulasi.

Usia ibu juga mempengaruhi kesiapan toilet training pada anak. Ibu yang berusia dewasa muda masih belum memiliki pengalaman yang cukup mengenai perawatan anak khususnya dalam penerapan toilet training. Kenyataannya ibu dengan usia dewasa muda ini masih memiliki ketergantungan yang lebih terhadap orang tuanya, bila dibandingkan dengan ibu yang berusia dewasa tua. Terbukti ibu dengan usia dewasa muda masih dominan mempercayakan orang tuanya dalam segala hal yang berhubungan pengasuhan dan perawatan anaknya.

Anak usia 25-36 bulan memang memiliki kesiapan fisik dan kesiapan kognitif yang lebih baik jika dibandingkan dengan anak usia 18-24 bulan. Namun, dari segi perkembangan psikologi pada usia 25-36 bulan justru kurang mendukung adanya pelaksanaan toilet training karena pada masa usia ini anak sudah mulai melakukan pemberontakan terhadap orang tua jika ada hal yang tidak sesuai dengan keinginan atau kemauannya. Sehingga dengan adanya kondisi tersebut dapat menganggu pelaksanaan toilet training pada anak.

Jenis kelamin anak merupakan salah satu faktor yang juga dapat mempengaruhi kesiapan toilet training pada anak. Anak perempuan sesungguhnya lebih displin dalam penerapan toilet training hanya saja pada hasil penelitian ini diperoleh jenis kelamin perempuan lebih dominasi dari laki-laki sehingga jumlah perbandingan antara laki-laki dan perempuan tidak seimbang. Hasil penelitian ini juga didapatkan bahwa sebagian besar responden memiliki kesiapan toilet training yang kurang, oleh karena itu hasil penelitian ini bertolak belakang dengan teori yang diungkapkan oleh Gilbert (2008), bahwa anak laki-laki cenderung lebih lambat dalam penguasaan kontrol terhadap kandung kemihnya dibandingkan anak perempuan. Hal ini disebabkan sistem syaraf anak laki-laki berkembang lebih lama daripada anak perempuan, anak perempuan dapat mulai menguasai keinginan buang airnya pada umur 18 bulan, sementara anak laki-laki baru menguasai saat berumur 22 bulan.

Hubungan Penggunaan Diapers dengan Kesiapan Toilet Training Pada Anak Toddler (18-36 bulan) 
Dari Hasil uji Rank Spearman dengan cara menggunakan SPSS versi 17.0 menunjukkan $\mathrm{p}<\alpha=0.000<0.05$ maka H0 ditolak artinya ada hubungan penggunaan diapers dengan kesiapan toilet training pada toddler (18-36 bulan) di RW 04 Desa Keboan Anom Kecamatan Gedangan Kabupaten Sidoarjo.

Dengan penggunaan diapers yang terlalu lama pada anak dapat mengakibatkan dampak negatif terhadap kesiapan toilet training pada anak. Karena dengan kebiasaan menggunakan diapers maka seorang anak akan mendapatkan kenyamanan dari kebiasaan itu, sehingga membuat anak menjadi sulit juga untuk meninggalkan ketergantungan terhadap penggunaan diapers. Sehingga lama kelamaan kebiasaan dari penggunaan diapers itu jika dibiarkan maka akan menghambat dari pelaksaan toilet training. Berbeda dengan anak yang terbiasa tidak menggunakan diapers maka anak tidak akan mendapatkan kenyamanan ketika sudah BAK/BAB karena merasa risih sehingga melatih stimulus dan sensitifitas anak dalam hal mengutarakan atau menyampaikan pada orang tua jika BAK/BAB dan dapat menunjang dari kesiapan anak untuk toilet training. Sehingga dapat disimpulkan bahwa penggunaan diapers yang terlalu sering dan lama dapat menyebabkan kesiapan toilet training pada anak kurang. Hal ini sesuai dengan teori yang diungkapkan oleh Warner \& Kelly (2006) bahwa salah satu yang dapat mempengaruhi kesiapan toilet training adalah kebiasaan (penggunaan diapers).

\section{Simpulan}

Berdasarkan tujuan dan hasil yang akan dicapai dalam proses penelitian ini maka dapat disimpulkan sebagai berikut :

1. Penggunaan diapers pada anak toddler ( 18-36 bulan) di RW 04 Desa Keboan Anom Kecamatan Gedangan Kabupaten Sidoarjo hampir setengahnya memilih menggunakan diapers selama 12-24 jam/hari.
2. Kesiapan toilet training pada anak toddler (18-36 bulan) di RW 04 Desa Keboan Anom Kecamatan Gedangan Kabupaten Sidoarjo sebagian besar masih memiliki kesiapan yang kurang.

3. Ada hubungan penggunaan diapers dengan kesiapan toilet training pada toddler di RW 04 Desa Keboan Anom Kecamatan Gedangan Kabupaten Sidoarjo.

\section{DAFTAR PUSTAKA}

Adriana, D. (2011). Tumbuh Kembang \& Terapi Bermain Pada Anak. Jakarta, Salemba Medika.

Alimul, A.Aziz. (2008). Pengantar Ilmu Kesehatan Anak untuk Pendidikan Kebidanan. Jakarta, Salemba Medika.

Anna, Lusia. (2011). Segera Ajarkan Balita Toilet Training. http://female.kompas.com/read/201 1/08/10/08042557/Segera.Ajarkan.

Balita.Toilet .Training. Diakses pada tanggal 30 April 2012.

Anne, Marrie M. (2007). Panduan Lengkap Perawatan Bayi Dan Anak. Yogyakarta, Diglossia Media.

Anonim. (2008). Bab II Tinjauan Pustaka Diapers. Http://digilib.unimus.ac.id /files/disk1/111/jtptunimus/-gdlifachozina-5517-3-babii.pdf. Diakses pada tanggal 28 April 2012.

Anonim. (2011). Cerdas Memilih Popok Anak. www.info-sehat.com. Diakses pada tanggal 30 April 2012

Anonim. (2012). Mengenal Berbagai Jenis Popok Dan Kelebihannya- Ibu \& Balita. www.ibudanbalita.com. Diakses pada tanggal 30 April 2012

Arikunto, S. (2002). Prosedur Penelitian Suatu Pendekatan. Jakarta, Rineka Cipta.

Douglas, Ann. (2009). Buku Batita Terlengkap. Jakarta, Dian Rakyat. 
Fitrianty, W. (2010). Skripsi Hubungan Pengetahuan Ibu Dengan Pelaksanaan Toilet Training Pada Anak Usia 2-4 Tahun. Surabaya, Sikes Yarsis.

Gallant dan Goldstein. (2011). Buku Pintar Mengasuh Anak. Jakarta, Light Publising.

Gilbert, Jane. (2003). Latihan Toilet. Jakarta, Erlangga.

Mubarok, Wahid I. (2007). Promosi Keshatan. Yogyakarta, Graha Ilmu.

Muscari, Mary E. (2005). Keperawatan Pediatrik Edisi Ke-3. Jakarta, EGC.

Notoatmodjo, S. (2002). Metode Penelitian Kesehatan, Edisi Revisi. Jakarta, Rineka Cipta.

Notoatmodjo, S. (2007). Promosi Kesehatan dan Ilmu Perilaku. Jakarta, Rineka Cipta.

Nurdiansyah, Nia. (2011). Buku Pintar Ibu \& Bayi. Jakarta, Gramedia.

Nursalam. (2003). Konsep dan Penerapan Metodologi Penelitian Ilmu Keperawatan. Jakarta, Salemba Medika.

Potter, Patricia A. (2005). Buku Ajar Fundamental Keperawatan (Konsep, Proses, dan Praktik) Vol 2. Jakarta, EGC.

Pusparini, W. (2010). Skripsi Hubungan Pengetahuan Ibu Tentang Toilet Training Dengan Perilaku Ibu Dalam Melatih Toilet Training Pada Anak Usia Toddler Di Desa Kadokan Sukoharjo. Surakarta, Universitas Muhammadiyah.

Satyanegara, Surya. (2004). Panduan Lengkap Perawatan Untuk Bayi dan Balita. Jakarta, Arcan.

Supartini, Y. (2004). Buku Ajar Konsep Dasar Keperawatan Anak. Jakarta, EGC.

Suparno, P. (2003). Teori Perkembangan Kognitif Jean Piaget. Jakarta, Gramedia.

Thompson, J. (2003). Toddler Care : Pedoman Lengkap Perawatan Batita. Jakarta, Erlangga.
Warner, P \& Kelly, P. (2006). Mengajari Anak Pergi Ke Toilet. Jakarta, Arcan.

Wicaksono, H. (2005). Kapan SebaiknyaMemulai Toilet Training Pada Anak ?. Http://wrmindonesia.org/index2ph p?option $=$ content $\& d o \_p d f=1 \& i d=5$ 61. Diakses pada tanggal 30 April 2012

Wong, Donna L. (2003). Pedoman Klinis Keperawatan Pediatrik. Jakarta, EGC.

Yessi. (2007). Toilet Traing Supaya Anak Tak Bikin Pusing. Http://yessie_multiply.com.

Diakses pada tanggal 16 April 2012

Yayat. (2009). Jenis-jenis Popok Kain. Http://poqpok.multiply.com/ journal /item/1 /Jenisjenis_popok_kain. Diakses pada tanggal 30 April 2012 